\title{
The Use of a Gunn-Bellani Distillator to Determine Net Radiative Flux in West Africa
}

\author{
J. A. Davies \\ King's College, London \\ 11 December 1964 and 4 March 1965
}

\section{Introduction}

In energy and moisture studies at the base of the atmosphere, the net radiative flux (i.e., the difference between incoming and outgoing fluxes of short-wave and long-wave radiation) is a vital term. Until recently the problem of its measurement has been acute and there have been several attempts to arrive at estimates from empirical formulae (Penman, 1948; Budyko, 1956) using common climatological data such as air temperature, humidity and cloudiness. Another approach seeks to estimate the parameter from insolation or net shortwave flux alone in a simple linear regression equation. Such linear trends have been demonstrated by Monteith (1961), Scholte-Ubing (1961), Orvig (1961) and Davies (1963). The net long-wave flux may be ignored on the assumptions that the short-wave fluxes account for the greater proportion of the net flux and that there is an high covariance between the latter and the other two fluxes. It is implied in all these studies that solarimetric measurements of the short-wave input are available. In many parts of the world they are not, particularly in the humid tropics. This is the case in Nigeria. In this paper, an approximation of net flux is sought from measurements by a simple instrument. The instrument is the Gunn-Bellani distillator, which has been used successfully in East Africa to provide insolation estimates after calibration against a solarimeter (Pereira, 1959). A close relationship has been demonstrated between net flux and insolation and it follows that there should be a usable relationship between net flux and distillator measurements. Here a comparison is made between a spherical receiver solely sensitive to sky radiation for wavelengths $<3 \mu$ with a fat horizontal net radiometer sensitive to all wavelengths. In spite of this very differ- ent geometry and spectral response, a workable correlation is found.

\section{Instrumentation}

In Nigeria, there are only two stations with any record of net flux although there are nineteen insolation stations equipped with distillator. The two stations are at the West African Institute for Oil Palm Research (W.A.I.F.O.R.) near Benin $\left(06^{\circ} 33^{\prime} N, 05^{\circ} 37^{\prime} \mathrm{E}\right)$ and at the University of Ibadan $\left(07^{\circ} 28^{\prime} \mathrm{N}, 03^{\circ} 54^{\prime} \mathrm{E}\right)$. A daily record is available from February 25th to May 22nd 1962 for Benin, and from April 13th to August 18th 1964 for Ibadan.

Both stations are equipped with the same model of Gunn-Bellani distillator (Baird and Tatlock Ltd., London). The instrument expresses insolation in terms of the amount of water $(\mathrm{ml})$ distilled from within a blackened, hollow sphere exposed to the sun and sky. Detailed descriptions and analyses of performances have been forwarded by Pereira (1959) and Monteith and Szeics (1960).

At Benin net flux was measured by a Beckman and Whitley radiometer (Model N188, Beckman and Whitley Inc., San Carlos, California). At Ibadan a Funk (C.S.I.R.O.) net radiometer (Model CN.1, Middleton and Co. Pty. Ltd., Melbourne) is in use (Funk, 1959). The output of the radiometer at both stations is recorded by a self-balancing potentiometric Kent "Multelec" recorders (George Kent Ltd., Luton). The Ibadan one is equipped with integrator.

\section{Results}

In this analysis, simple linear regression and correlation coefficients are determined between daily values of daytime net flux (langleys) and the corresponding in- 
solation $(\mathrm{ml})$. The standard error of estimate $(s)$ was calculated to show the limits within which values are likely to lie, and the square of the correlation coefficient $\left(r^{2}\right)$ to show the proportion of variance accounted for by the regression. The respective pairs of daily data are plotted in Fig. 1. The linear regressions are

$$
R=19.6 D+20.3, r^{2}=0.95, s=16.1
$$

For Benin, and

$$
R=18.3 D+25.8, r^{2}=0.90, s=25.4,
$$

for Ibadan. Grouping the two sets of data as one, the equation is

$$
R=19.3 D+19.0, r^{2}=0.95, s=21.2,
$$

where $R=$ net radiative flux (gcal. $\left.\mathrm{cm}^{-2} \mathrm{day}^{-1}\right)$

$$
D=\text { distillate }\left(\text { ml.day }{ }^{-1}\right) .
$$

The trends are remarkably linear, the scatter close and the correlation high in both cases. The regression coefficients are very similar for the two sets of data such that the regression equation describing both sets of data as one would serve equally well for each station. From these relationships net flux can be calculated to within a probable maximum error of \pm 32 to 50 langleys (i.e., \pm twice the standard error of estimate). As most values are likely to be much less than these limits, the estimates are considered very satisfactory.

The paradox that net flux is positive when insolation is zero is attributed to the high threshold value of the distillator. This phenomenon has been reported by Pereira (1959) and discussed by Monteith and Szeicz (1960) who found it to be temperature dependent.

In spite of the good relationship between the two variables, there are certain limitations to the application of the equations:

(1) The distillator can only give estimates of daytime net flux whereas the latter is a continuous 24 hour parameter. For certain purposes a daytime estimate is sufficient, particularly in water loss investigations where the positive net flux is much more important than the negative nocturnal flux.

(2) The radiation balance equation contains a reflectivity term which is important as it can vary widely with different types of surface, both natural and artificial, within an area of uniform solar input. In the case of the two stations considered here, the reflectivity is approximately the same as both are located in the same general latitude and both radiometers are sited over grass. In other areas of Nigeria, particularly in the north, the prolonged, severe dry season would result in very different values of surface reflectivity. A variation in regression coefficients could be expected if the experiment were tried elsewhere.

(3) Because of (2), and because there can be different responses of distillator to radiation, the regression equa-
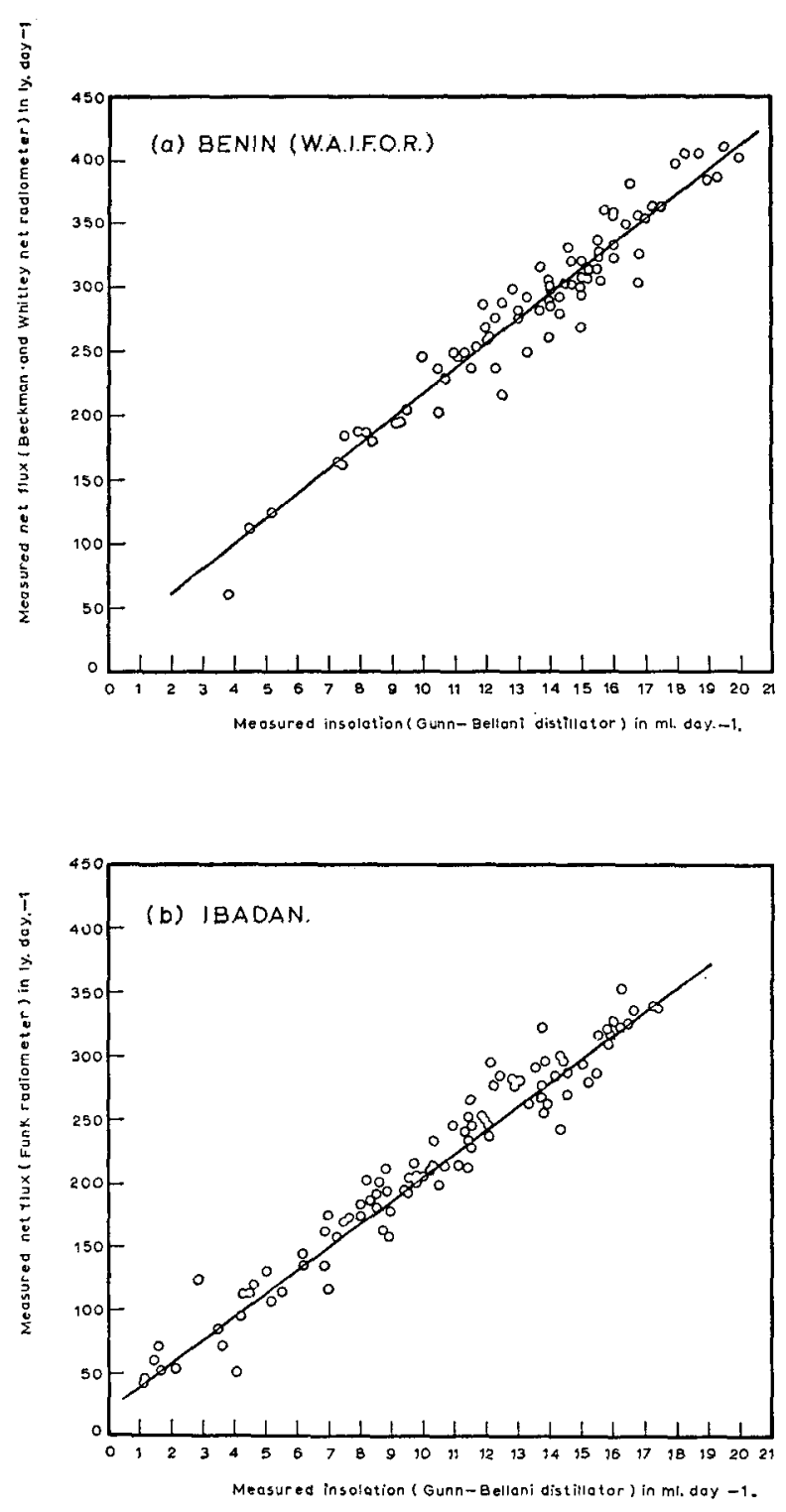

FIG. 1. The relationship between net flux and insolation (distillate). (a) at the West African Institute for Oil Palm Research (W.A.I.F.O.R.) near Benin, and (b) at the University of Ibadan.

tions obtained for Benin and Ibadan data cannot be extended confidently to other stations equipped with distillators. Individual calibration would be ideal but if the relationships in this paper could be substantiated at a few other stations in different climatic regions, their validity could be established.

Acknowledgments. I am indebted to the Nigerian Meteorological Service for making the Funk net radiometer available to me and for providing daily GunnBellani distillator data for Benin; and to the Director of Benin W.A.I.F.O.R. for forwarding the recorder charts and calibration information for the Beckman and Whitley radiometer. 


\section{REFERENCES}

Budyko, M. I., 1956: The Heat Balance of the Earth's Surface. (English translation: N. A. Stepanova, 1958) Office of Tech. Serv., U. S. Dept. of Commerce, Washington, $259 \mathrm{pp}$.

Davies, J. A., 1963: Net radiation studies in the Schefferville area. Arctic, 16, 41-46.

Funk, J. P., 1959: Improved polythene-shielded net radiometer. J.Sci. Instr., 36, 267-270.

Monteith, J. L., and G. Szeicz, 1960: The performance of a GunnBellani radiation integrator. Quart. J. R. Meteor. Soc., 86, 371, 91-94.
- and - 1961: The radiation balance of bare soil and vegetation. Quart. J. R. Meteor. Soc., 87, 372, 159-170.

Orvig, Svenn, 1961: Net radiation flux over sub-Arctic surfaces. J. Meteor., 18, 199-203.

Penman, H. L., 1948: Natural evaporation from open water, bare soil, and grass. Proc. Roy. Soc. London, A. 193, 120-146.

Pereira, H. C., 1959: Practical field instruments for estimation of radiation and of evaporation. Quart. J. R. Meteor. Soc., 85, 253-261.

Scholte-Ubing, D. W., 1961: Solar and net radiation, available energy and its influence on evapotranspiration from grass. Nelh. J. Agric.Sci., 9, 81-93. 